\title{
Consideration of Moving Tooth Load in Gear Crack Propagation Predictions
}

U.S. Army Research Laboratory, NASA Glenn Research Center, Cleveland, $\mathrm{OH} 44135$

Lisa E. Spievak Paul A. Wawrzynek Anthony R. Ingraffea

Cornell Fracture Group, Cornell Uniyersity, lthaca, NY 14853
Robust gear designs consider not only crack initiation, but crack propagation trajectories for a fail-safe design. In actual gear operation, the magnitude as well as the position of the force changes as the gear rotates through the mesh. A study to determine the effect of moving gear tooth load on crack propagation predictions was performed. Twodimensional analysis of an involute spur gear and three-dimensional analysis of a spiralbevel pinion gear using the finite element method and boundary element method w'ere studied and compared to experiments. A modified theory for predicting gear crack propagation paths based on the criteria of Erdogan and Sih [18] was investigated. Crack simulation based on calculated stress intensity factors and mixed mode crack angle prediction techniques using a simple static analysis in which the tooth load was located at the highest point of single tooth contact was validated. For three-dimensional analysis, however, the analysis was valid only as long as the crack did not approach the contact region on the tooth. [DOI: 10.1115/1.1338118]

\section{Introduction}

Effective gear designs balance strength, durability, reliability, size, weight, and cost. Even effective designs, however, can have the possibility of gear cracks due to fatigue. In addition, truly robust designs consider not only crack initiation, but crack propagation trajectories. As an example, crack trajectories that propagate through the gear tooth are the preferred mods of failure compared to propagation through the gear rim. Rim failures will lead to catastrophic events and should be avoided. Analysis tools that predict crack propagation paths can be a valuable aid to the designer to prevent such catastrophic failures.

Pertaining to crack analysis, linear elastic fracture mechanics applied to gear teeth has become increasingly popular. The stress intensity factors are the key parameters to estimate the characteristics of a crack. Analytical methods using weight function techniques to estimate gear tooth stress intensity factors have been developed $[1,2]$. Numerical techniques such as the boundary element method and finite element method have also been studied $[3,4]$. Based on stress intensity factors, fatigue crack growth and gear life predictions have been investigated [5-8]. In addition, gear crack trajectory predictions have been addressed in a few studies [9-13].

From publications on gear crack trajectory predictions, the analytical methods have been numerical (finite or boundary element method) while solving a static stress problem. In actual gear applications, however, the load moves along the tooth, changing in both magnitude and position. No work has been done investigating the effect of this moving load on crack trajectories.

The objective of the current work is to study the effect of moving gear tooth load on crack propagation predictions. Twodimensional analysis of an involute spur gear using the finite element method is discussed. Also, three-dimensional analysis of a spiral-bevel pinion gear using the boundary element method is discussed. A quasi-static numerical simulation method is presented in which the gear tooth engagement is broken down into multiple load steps and analyzed separately. Methods to analyze the steps are discussed, and predicted crack shapes are compared to experimental results.

Contributed by the Power Transmission \& Gearing Committee for publication in the JOURNAL OF MECHANICAL DESIGN. Manuscript received May 2000; revised Oct. 2000. Associate Editor: J. Gao.

\section{Two-Dimensional Analysis}

Gear Modeling. The two-dimensional analysis was performed using the FRANC (FRacture ANalysis Code) computer program developed by Wawrzynek [14]. The program is a general-purpose finite element code for the static analysis of twodimensional cracked structures. The program uses principles of linear elastic fracture mechanics and is capable of analyzing plane strain, plane stress, or axisymmetric problems. A unique feature of the program is the ability to model cracks and crack propagation in a structure. A rosette of quarter-point, six-node, triangular elements is used around the crack tip to model the inverse squareroot stress singularity. Mode I and mode II stress intensity factors, $K_{I}$ and $K_{I I}$, respectively, can be calculated using a variety of methods. (As a refresher, mode I loading refers to loads applied normal to the crack plane and tends to open the crack. Mode II refers to in-plane shear loading.) The stress intensity factors quan tify the state of stress in the region near the crack tip. In the program, the stress intensity factors can be used to predict the crack propagation trajectory angles, again using a variety of methods. In addition, the program has a unique re-meshing scheme to allow automated processing of the crack simulation.

A spur gear from a fatigue test apparatus was modeled to demonstrate the two-dimensional analysis. The modeled gear had 28 teeth. a $2 U$ pressure angle, a module of $3.175 \mathrm{~mm}$ (diametral pitcil us $\left.0 \mathrm{~m}^{-1}\right)$, and a face width of $6.35 \mathrm{~mm}(0.25 \mathrm{in})$. The gear had a backup ratio (defined as the rim thickness divided by the tooth height) of 3.3. The complete gear was modeled using mostly 8-node, plane stress, quadrilateral finite elements. For improved accuracy, the mesh was refined on one of the teeth in which a crack was inserted. The total model had 2353 elements and 7295 nodes. Four hub nodes at the gear inner diameter were fixed to ground for boundary conditions. The material used was steel.

Tooth Loading Scheme. To determine the effect of gear tooth moving load on crack propagation, the analysis was broken down into eighteen separate load cases (Fig. 1). An initial crack of $0.26 \mathrm{~mm}(0.010 \mathrm{in})$ in length was placed in the fillet of tooth 2 . normal to the surface, at the location of the maximum tensile stress (uncracked condition). Six load cases were analyzed separately with the load on the tooth ahead of the cracked tooth, six on the cracked tooth, and six on the tooth after. The calculated stress intensity factors for unit loads at each of the load positions is shown in Fig. 2. These stress intensity factors were calculated 


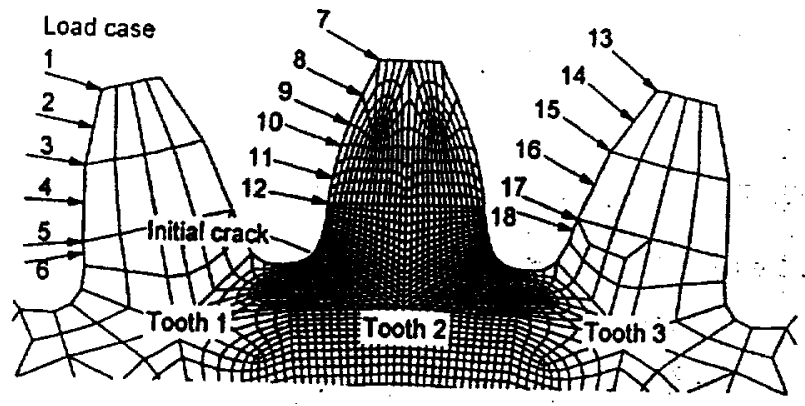

Fig. 1 Location of load cases for finite element mesh

using the J-integral technique [15] Loads on tooth tooth) produced tension low to the ince toward the toad cases 12 to 7, Fig. 2b) due to the increased load lever arm. Loads on tooth 3 also produced tension at the crack tip, but at an order of magnitude less than those produced from the loads on tooth 2 (Fig. 2c). Loads on tooth 1 gave compression to the crack tip as shown by the negative $K_{l}$ 's
(Fig. 2a).

Next, the actual load magnitudes on the gear tooth were considered as it went through the mesh. Computer program DANST (Dynamic ANalysis of Spur gear Transmission, [16]) was used for the analysis. This program is based on a four-degree-of-freedom, torsional, lumped mass model of a gear transmission. The model includes driving and driven gears, connecting shafts, a motor, and a load. The equations of motion for this model were derived from * basic gear geometry, elementary vibration principles, and timevarying tooth stiffnesses. For simplicity, the static gear tooth loads of the solution were determined (Fig. 3). These loads were determined from well-established gear tooth stiffness principles and static equilibrium. The loads are shown as a function of gear rotation for a driver torque of $68 \mathrm{~N}-\mathrm{m}$ ( $599 \mathrm{in}-\mathrm{lb})$. Tooth 2 began contact at a gear rotation of $10^{\circ}$. As the gear rotation increased, the load on tooth 2 gradually increased. Tooth 1 and 2 shared the
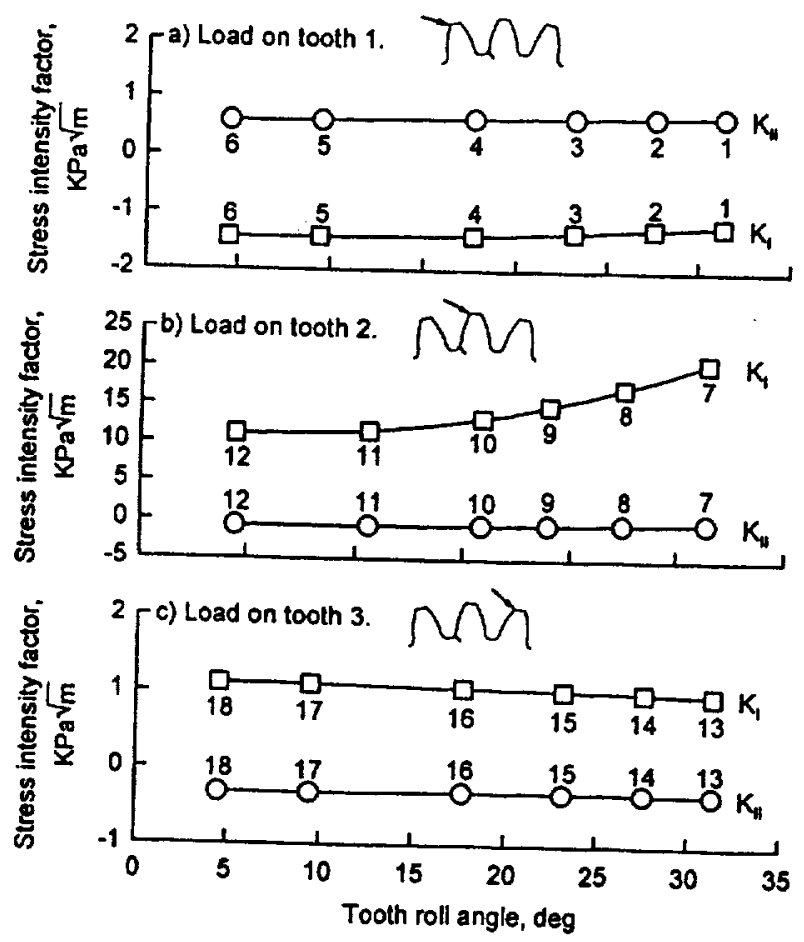

Fig. 2 Mode I and mode il stress Intensity factors for a unit load and an initlal crack of $0.26 \mathrm{~mm}$

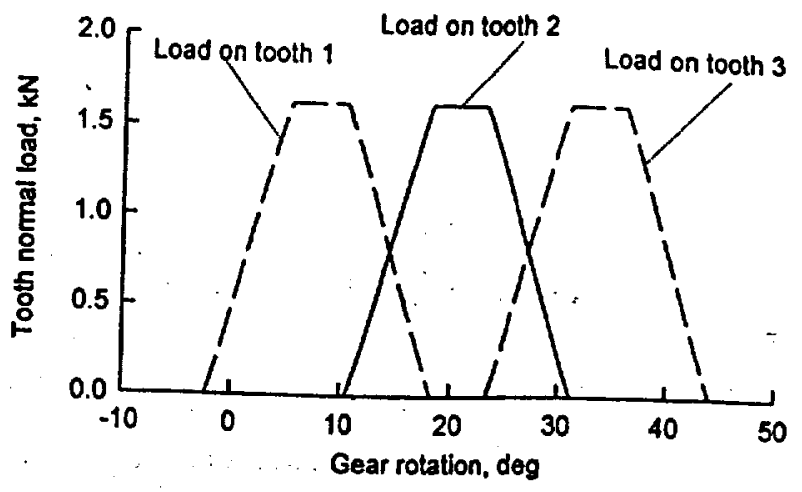

Fig. 3 DANST computer program output of static gear tooth load, $68 \mathrm{~N}-\mathrm{m}$ driver torque

load for a rotation from 10 to $18^{\circ}$. From 18 to $23^{\circ}$, tooth 2 carried the complete load. At $23^{\circ}$, tooth 2 is considered at its highest point of single tooth contact (HPSTC).

The stress intensity factors as a function of gear rotation were then determined by multiplying the stress intensity factors determined from the units loads (Fig. 2) by the actual tooth loads (Fig. 3) and applying superposition since linear elastic fracture mechanics was used. The results are shown in Fig. 4. As expected, the mode I stress intensity factor (Fig. 4a) was mostly influenced by the load on tooth 2 . Note that the largest value of $K_{I}$ occurred at the HPSTC. Also note that the magnitude of $K_{I}$ (Fig. 4a) was much larger than that of $K_{I l}$ (Fig. $4 b$ ). This implied that $K_{l}$ was the driving force in the crack propagation. $K_{I}$, however, affected the crack propagation angle as will be shown in the next section.

Crack Propagation Simulation. From Williams [17], the tangential stress near a crack tip, $\sigma_{\theta \theta}$, is given by

$$
\sigma_{\theta \theta}=\frac{1}{\sqrt{2 \pi r}}\left(K_{1} \cos ^{3} \frac{\theta}{2}-3 K_{11} \sin \frac{\theta}{2} \cos ^{2} \frac{\theta}{2}\right)
$$

where $r$ and $\theta$ are polar coordinates with the origin at the crack tip. Erdogan and Sih [18] postulated that crack extension starts at the crack tip and grows in direction of the greatest tangential stress. The direction of the greatest tangential stress is determined by taking the derivative of $\mathrm{Eq}$. 1 with respect to $\theta$, setting the expression equal to 0 for, then solving $\theta$. Performing the math, this predicted crack propagation angle, $\theta_{m}$, is given by

$$
\theta_{m}=2 \tan ^{-1}\left[\frac{\frac{K_{I}}{K_{I}} \pm \sqrt{\left(\frac{K_{l}}{K_{I I}}\right)^{2}+8}}{4}\right]
$$

From Eq. 2, the predicted crack propagation angle is a function of the ratio of $K_{l}$ to $K_{l l}$. Erdogan and Sih [18] used brittle plexiglass plates under static loading to validate their proposed theorems (i.e., the ratio of $K_{1}$ to $K_{i l}$ was constant). For the gear problem in the current study, however, the ratio of $K_{I}$ to $K_{I I}$ was not constant during gear rotation. This is shown in Fig. $4 c$ (actually plotted as the ratio $K_{\| /}$to $K_{l}$ for clarity). In addition, Fig. $4 d$ gives the calculated $\theta_{m}$ from $\mathrm{Eq} .2$ as a function of gear rotation.

In order to simulate gear crack propagation, a modification to the Erdogan and Sih theory was postulated in the current study. This modified theory states that the crack extension starts at the crack tip and grows in the direction of the greatest tangential stress as seen during engagement of the gear teeth. The procedure to calculate the crack direction is as follows: 1) $K_{I}$ and $K_{\|}$are determined as a function of gear rotation (Figs. $4 a$ and $4 b$, as described in the previous section), 2) the ratio of $K_{l}$ to $K_{l l}$ as a function of gear rotation is determined (Fig. 4c), 3) $\theta_{m}$ (using Eq. 2) as a function of gear rotation is determined (Fig. 4d), 4) $\sigma_{\theta \theta}$ 

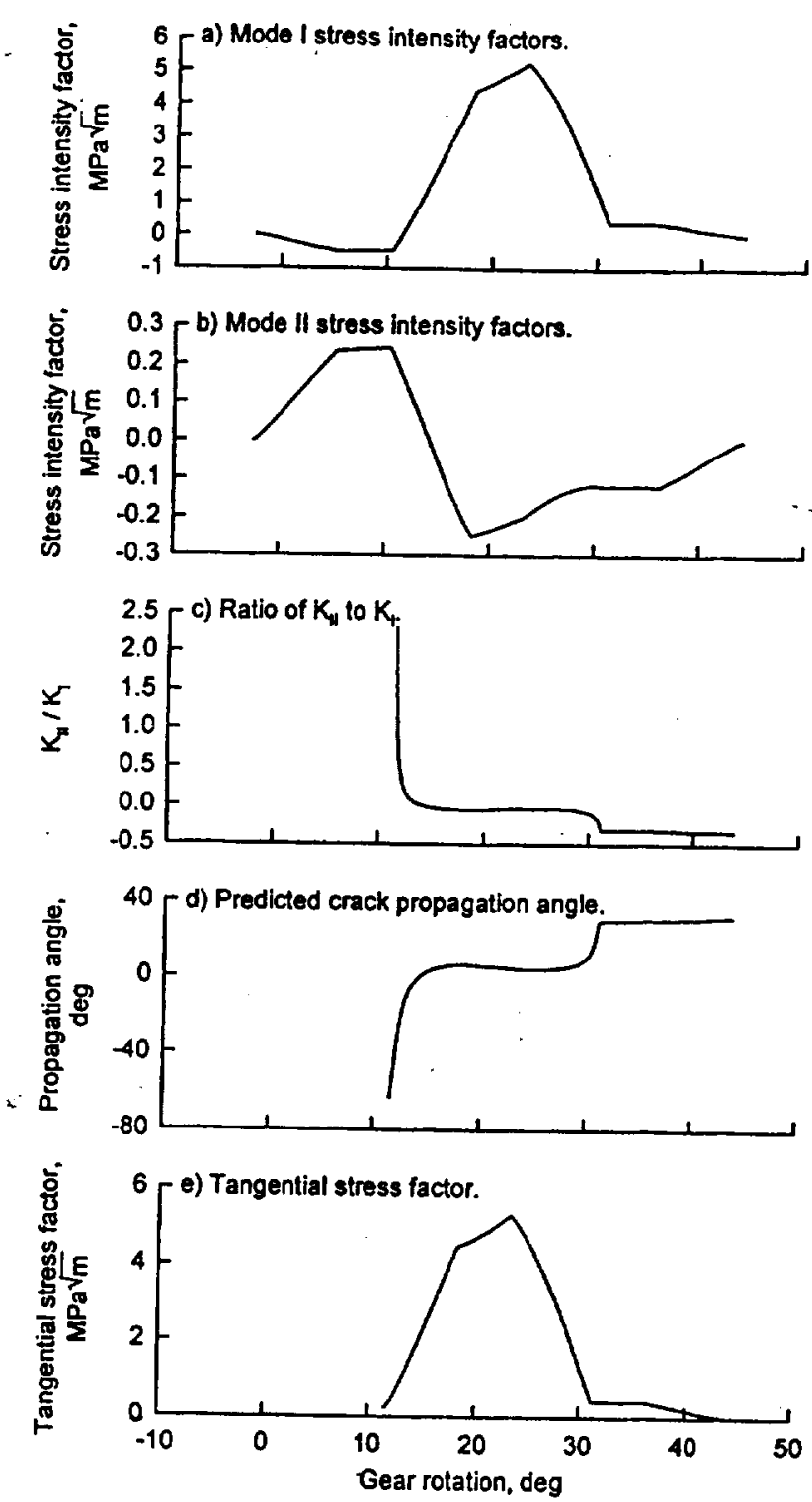

Fig. 4 Stress intensity and tangential stress factors as a function of gear rotation, $68 \mathrm{~N}-\mathrm{m}$ driver torque, $0.26 \mathrm{~mm}$ initial crack size

(using Eq. 1) as a function of gear rotation is determined (Fig. 4e), 5) the predicted crack direction is the value of $\theta_{m}$ for which $\sigma_{\theta \theta}$ is greatest during gear rotation.

For the gear example given, the tangential stress factor (defined as $\sigma_{\theta \theta} \sqrt{2 \pi r}$ ) is plotted as a function of gear rotation in Fig. $4 e$. This plot looks very similar to the mode I stress intensity factor plot (Fig. 4a) since $K_{l}$ was much larger than $K_{I I}$ (see Eq. 1). The tangential stress was largest at the HPSTC (gear rotation of $23^{\circ}$ ) and the predicted crack propagation angle at this gear rotation was $\theta_{m}=4.3^{\circ}$.

Using this propagation angle, the crack was extended by 0.26 $\mathrm{mm}$ ( $0.010 \mathrm{in})$, re-meshed, re-analyzed, and a new propagation angle was calculated using the method described above. This procedure was repeated a number of times to produce a total crack length of $2.38 \mathrm{~mm}(0.094 \mathrm{in})$. The $0.26-\mathrm{mm}$ crack extension length was based on prior experience in order to produce a smooth crack path. Figure 5 shows the stress intensity factors versus gear rotation for a number of crack lengths. Note that the mode I stress intensity factors looked similar but with increased magnitude as the crack length increased. In all cases, the selected crack propagation angles occurred when the tooth load was placed at the

HPSTC. Figure 6 shows a similar analysis but with a model of a thin-rimmed gear. Here, the gear was modeled based on the previous design, but with slots incorporated in the rim to simulate a thin-rimmed gear. The backup ratio for this model was 0.2. As seen, the magnitudes of the mode I stress intensity factors during tension (gear rotations 18 to $45^{\circ}$ ) were larger than that of the 3.3 backup ratio gear. Also, there was a significant increase in the compressive $K_{l}$ 's (gear rotation less than $18^{\circ}$ ) due to the increased compliance of the thin rim gear.

Comparison to Experiments. Figure 7 shows the results of the analysis compared to experimental tests in a gear fatigue apparatus. The original model (backup ratio of 3.3) as described before was compared along with models of backup ratio of 1.0
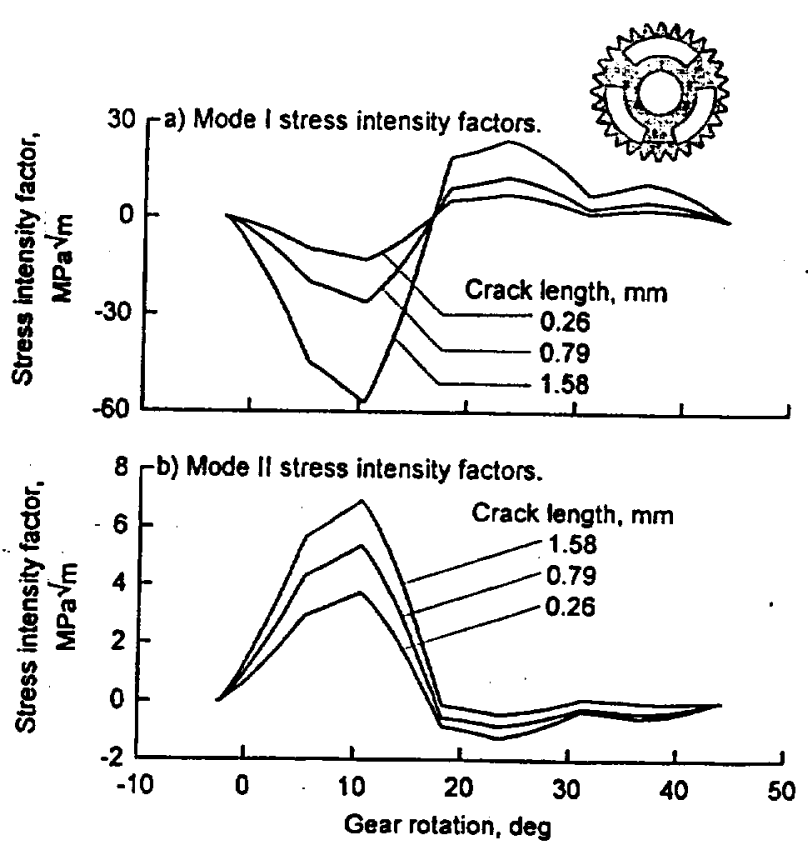

Fig. 6 Stress intensity factors from gear tooth crack propagation simulation, backup ratio -0.2 


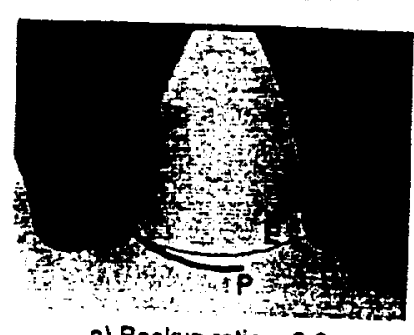

a) Backup ratio $=3.3$.

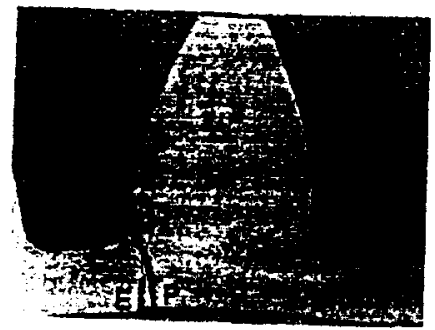

c) Backup ratio $=0.3$.

Fig. 7 Comparison of predicted gear tooth crack propagation paths with experimental results ( $P=$ predicted, $E=$ experiments)

and 0.3. These later two models were created using slots in the gear blank as previously described. The experiments were first reported by Lewicki and Ballarini [9]. Here, notches were fabricated in the tooth fillet region to initiate tooth cracking of test gears of various rim thicknesses. The gears were nu at 10,000 $\mathrm{rpm}$ and at a variety of increasing loads until tooth or rim fracture occurred. As seen from the figure, good correlation of the predicted crack trajectories to experimental results was achieved. For backup ratios of 3.3 and 1.0, tooth fractures occurred. For the backup ratio of 0.3 , rim fracture occurred.

As a final note, the analysis indicated that the maximum tangential stress at the crack tip always occurred when the tooth load was positioned at the HPSTC. Thus, for two-dimensional analysis, crack simulation based on calculated stress intensity factors and mixed mode crack angle prediction techniques can use a simple static analysis in which the tooth load is located at the HPSTC. This was based on a modification to the Erdogan and Sih crack extension theory and the fact that the mode I stress intensity factor was much larger than the mode II factor.

\section{Three-Dimensional Analysis}

Gear Modeling. The three-dimensional analysis was performed using the FRANC3D (FRacture ANalysis Code for 3 Dimensions) computer program developed by Wawrzynek [14]. This program uses boundary element modeling and principles of linear elastic fracture mechanics to analyze cracked structures. The geometry of three-dimensional structures with non-planar, arbitrary shaped cracks can be modeled. The modeling of a threedimensional cracked structure is performed through a series of programs. Structure geometry grid point data are imported to a solid modeler program. Here, appropriate curves and faces (or patches) are created from the grid data as well as a closed-loop surface geometry model. This surface model is then imported to the FRANC3D program for boundary element model preparation. The user can then mesh the geometry model using 3 or 6 node triangular surface elements, or 4 or 8 node quadrilateral elements. Boundary conditions (applied tractions and prescribed displacements) are applied on the model geometry over faces, edges, or points. Initial cracks, such as elliptical or penny shaped, can be inserted in the structure. After complete formulation, the model is shipped to a boundary element equation solver program. Once the displacement and traction unknowns are solved, the results are

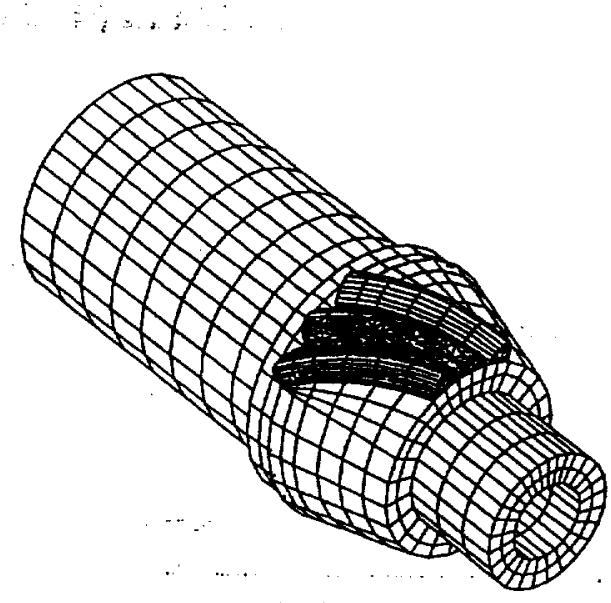

Fig. 8 Boundary element model of $\mathrm{OH}-58$ splral-bevel pinion

exported back to the FRANC3D program for post processing. Fracture analysis, such as stress intensity factor calculations, can then be performed.

The spiral-bevel pinion of the $\mathrm{OH}-58 \mathrm{C}$ helicopter main rotor transmission was modeled to demonstrate the three-dimensional analysis. The pinion had 19 teeth, a $20^{\circ}$ pressure angle, a $30^{\circ}$ mean spiral angle, a module of $3.66 \mathrm{~mm}$ (diametral pitch of 6.94 in $\left.^{-1}\right)$, and a face width of $31.75 \mathrm{~mm}$ (1.28 in). For OH-58 operation, the pinion mates with a 71-tooth spiral-bevel gear, operates at $6060 \mathrm{rpm}$, and has a design torque of $350 \mathrm{~N}-\mathrm{m}$ (3099 in-lb).

The boundary element model of the OH-58 pinion developed by Spievak [19] was used for the study. Three teeth, the rim cone, and the bearing support shafts were modeled (Fig. 8). The tooth surface and fillet coordinates were determined from the methods developed by Handschuh and Litvin [20] and Litvin and Zhang [21]. The mesh of the three teeth was refined for improved accuracy. A half-ellipse initial crack with major and minor diameters of 3.175 and $2.540 \mathrm{~mm}$, respectively $(0.125$ and $0.100 \mathrm{in})$, was placed in the fillet of the middle tooth normal to the surface. The crack was centered along the face width and centered along the fillet. The complete gear model had a total of about 2600 linear elements (both triangular and quadrilateral) and about 2240 nodes. For boundary conditions, the end nodes of the larger diameter shaft were fixed and the nodes on the outer diameter of the smaller diameter shaft were constrained in the radial directions. Again, the
material was steel.

Tooth Contact Analysis and Loading Scheme. Due to the geometrical complexities and three-dimensional action, numerical methods are required to determine the contact loads and positions on spiral-bevel teeth since no closed-form solution exists. The method of Litvin and Zhang [21] was used to determine the mean contact points on the spiral-bevel pinion tooth. The method modeled tooth generation and tooth contact simulation of the pinion and gear. With the mean contact points taken as the centers, contact ellipses were determined using Hertzian theory [22]. Figure 9 shows the estimated contact ellipses on the spiral-bevel pinion tooth. Fifteen separate ellipses (load cases) were determined, starting from the root of the pinion and moving toward the tooth tip and toe. Load cases 1-4 and 12-15 were double tooth contact regions while load cases $5-11$ were single tooth contact regions. Note that load case 11 corresponds to the load at the HPSTC. For each load case using the boundary element method, tractions were applied normal to the surface to the appropriate ellipse with the magnitude equal to the tooth normal force divided by the ellipse
area.

Crack Propagation Simulation. The procedure for the three dimensional crack propagation simulation of the OH-58 spiralbevel pinion was as follows. For each of the load cases of Fig. 9 , the mode I and mode II stress intensity factors were determined at 25 points along the crack front (note that for three-dimensions, 


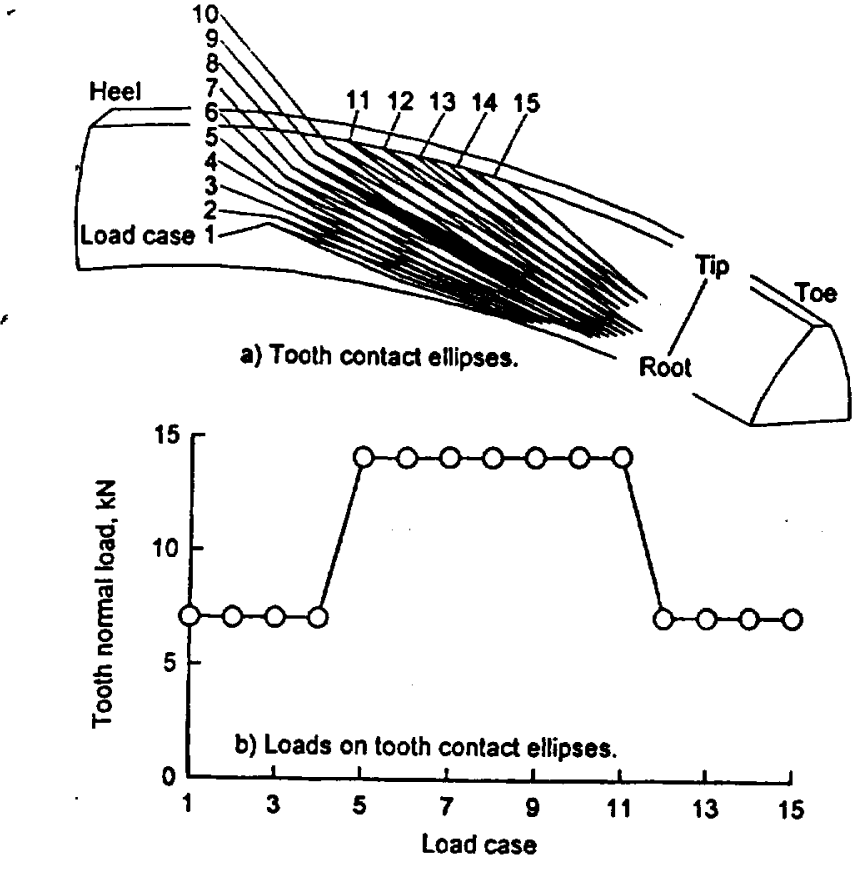

Fig. 9 Location of tooth contact ellipses and magnitude of load on $\mathrm{OH}-58$ spiral-bevel pinion tooth

there is a crack front, not just a crack tip as in two-dimensions). 'The extended crack directions at each of these 25 . points were determined using the modified Erdogan and Sih crack extension theory as described in the two-dimensional analysis. That is, as the cracked spiral-bevel pinion tooth was engaged in the mesh, the crack extension started at each point along the crack front and grew in direction of the greatest tangential stress at those points during mesh. The amount of crack extension at each point along the crack front was determined based on the Paris crack growth relationship [23] where

$$
a_{j}=a_{\max }\left(\frac{K_{l, j}}{K_{l, \max }}\right)^{n}
$$

where $a_{i}$ was the amount of extension of the $i_{, h}$ point along the crack front, $K_{t, i}$ was the mode I stress intensity factor of the $i_{t h}$ point along the crack front corresponding to the load case which gave the largest tangential stress for that front point, $K_{1, \max }$ was the value of the largest $K_{l, i}$ along the crack front, $a_{\max }$ was the maximum defined crack extension along the crack front, and $n$ was the Paris material exponent. From experience, the maximum extension size, $a_{\max }$, was set to $1.27 \mathrm{~mm}$ (0.050 in.). The Paris exponent, $n$, was set to 2.954 based on material tests for AISI 9310 steel by $\mathrm{Au}$ and $\mathrm{Ke}$ [24]. A third-order polynomial was then used to smooth the extended crack front. The new crack geometry was then re-meshed. After remeshing, the model was rerun and solved for stress intensity factors, and crack propagation directions. The above procedure was repeated a number of times to simulate crack growth in the gear tooth.

Table I gives results from the first four steps during this process. Note that step 0 corresponds to the initial half-ellipse crack. For steps 0 and 2, the largest tangential stress occurred at the HPSTC (load case 11) for the majority of the points along the crack front. For steps 1 and 3 , the largest tangential stress occurred at load cases $8,9,10$, or 11 .

Figure 10 shows the stress intensity factor distribution along the crack front for step 1 (crack area of $5.96 \mathrm{~mm}^{2}\left(0.009 \mathrm{in}^{2}\right)$ ). Similar to the spur gear analyses, the $K_{l}$ 's were larger as the load moved from the root to the tip due to the larger load lever arm. Other than absolute magnitude, the $K$, distributions along the crack front looked similar for the various load cases. Figure 11 depicts the
Table 1 Results of multiple load case crack simulation analysis.

\begin{tabular}{cccc}
\hline Step & $\begin{array}{c}\text { Crack area } \\
\left(\mathrm{mm}^{2}\right)\end{array}$ & Crack front point(s) & $\begin{array}{c}\text { Load case for } \\
\text { largest } \sigma_{\text {eo }}\end{array}$ \\
\hline 0 & 3.12 & 1 & 8 \\
1 & 5.96 & $2-25$ & 11 \\
& & $2,4-7,21,23-25$ & 99 \\
2 & 10.35 & $3,8-20,22$ & 10 \\
3 & 13.35 & $2-25$ & 11 \\
& & $7,9,20$ & 10 \\
& & $5-7,10-15,21,26,27$ & 11 \\
& & $1-4,8,16-19,22-25$ & 9 \\
\hline
\end{tabular}

stress intensity factors plotted against load case (at a point along the front, biased toward the toe, normalized position along the crack front of 0.83 ). This figure shows the simulated distribution as the pinion engages in mesh with the gear. Note again that the ratio of $K_{J}$ to $K_{I}$ was not constant during engagement.

Figure 12 shows exploded views of the pinion crack simulation after seven steps. It should be noted that the loading was placed only at the HPSTC for the last three steps. This was due to modeling difficulties encountered using the multi-load analysis. It was felt that this simplification did not significantly affect the results due to the smoothing curve-fit used. In addition, the tangential stress near the crack tip was either largest, or near its largest value, when the load was placed at the HPSTC.

Comparison to Experiments. Figure 13 shows the results of the analysis compared to experimental tests. The experimental tests were performed in an actual helicopter transmission test facility. As was done with the gear fatigue tests described before, notches were fabricated in the fillet of the $\mathrm{OH}-58$ pinion to pro-
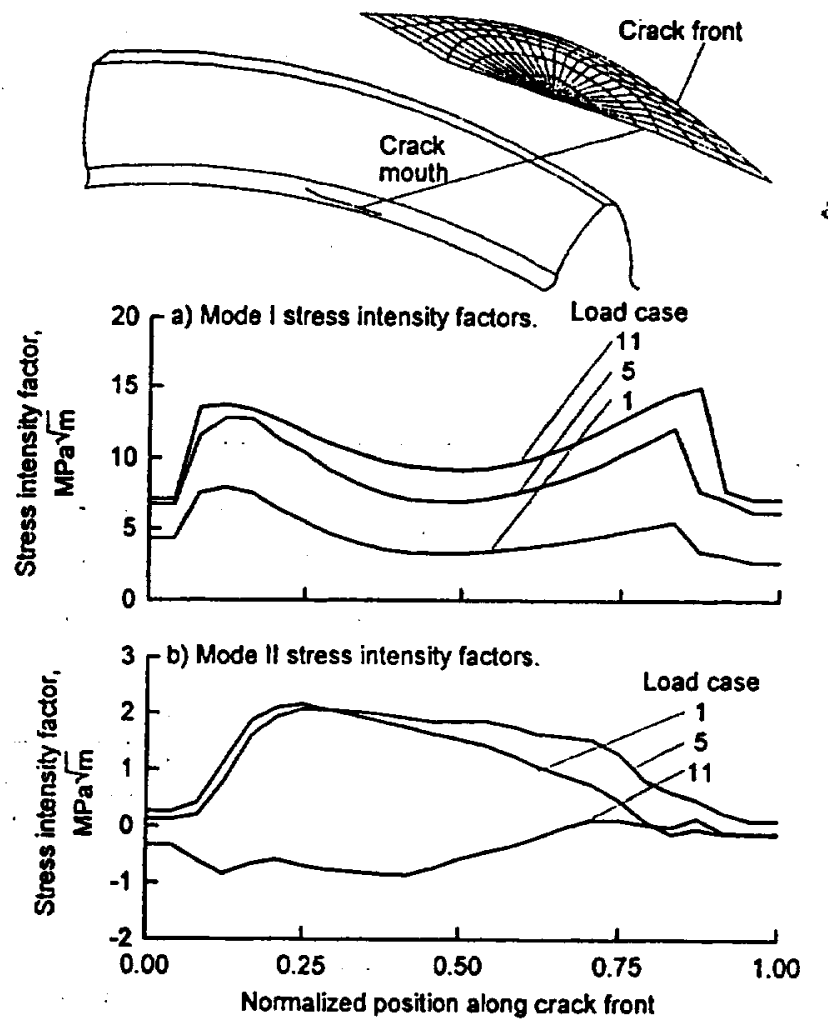

Fig. 10 Stress intensity factors from three dimensional $\mathrm{OH}-58$ pinion tooth crack propagation simulation; step 1, crack area $=5.96 \mathrm{~mm}^{2}$ 

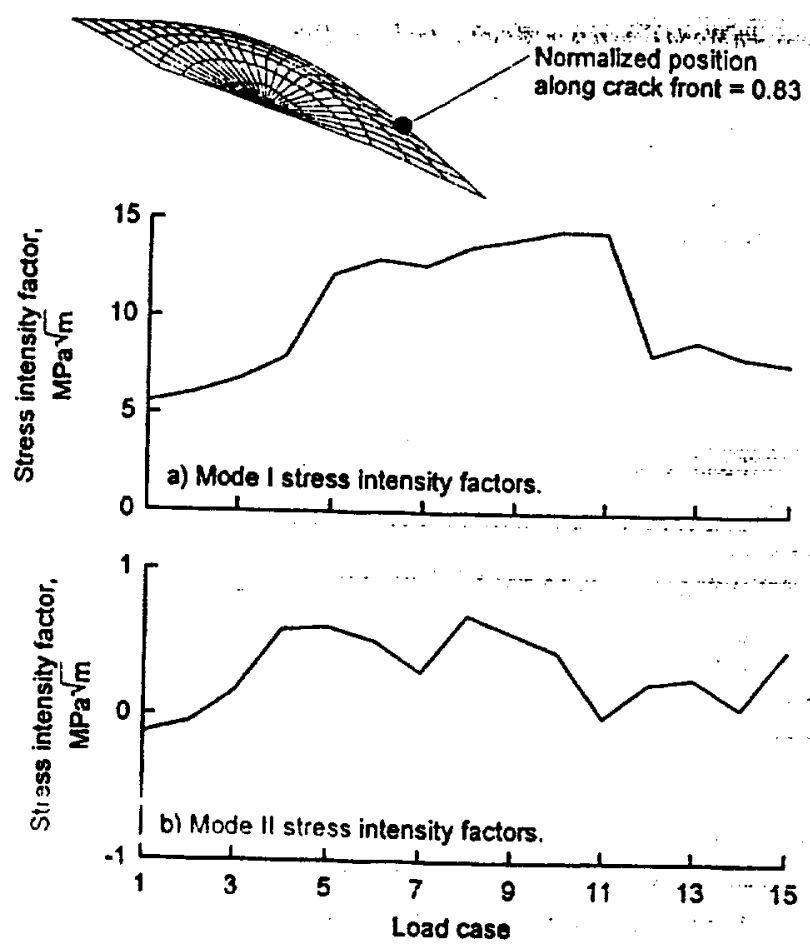

Fig. 11 Stress intensity factors from three-dimensional OH-58 pinion tooth crack propagation simulation; step 1, normalized position along crack front $=0.83$

:

"mote fatigue cracking. The pinion was run at full speed and a variety of increasing loads until failure occurred. Shown in the figure are three teeth that fractured from the pinion during the tests (Fig. 13b). Although the notches were slightly different in size, the fractured teeth had basically the same shape.

A side view of the crack propagation simulation is shown in Fig. 13a for comparison to the photograph of the tested pinion in Fig. $13 b$. From the simulation, the crack immediately tapered up toward the tooth tip at the heel end. This trend matched that seen

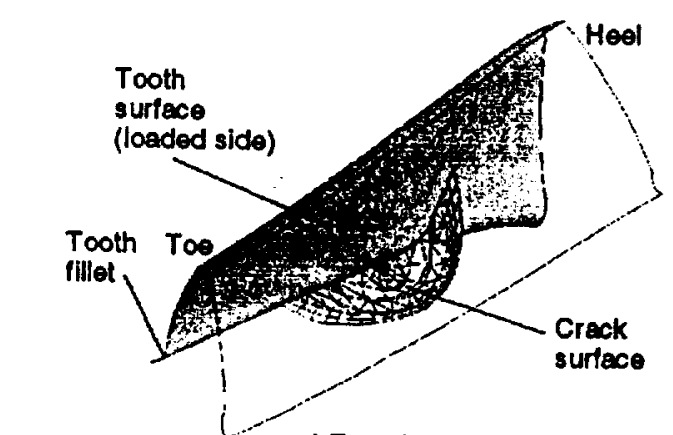

a) Toeside viow.

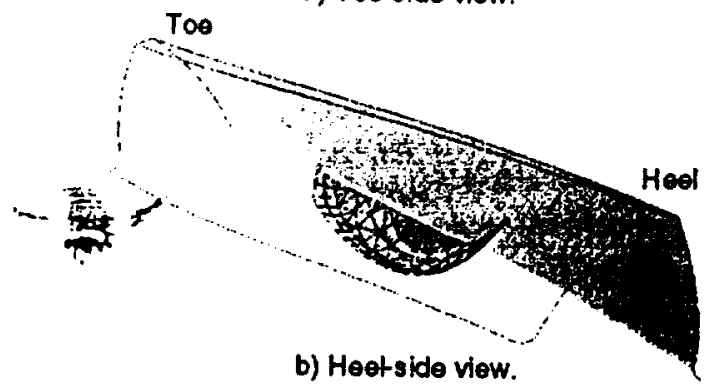

Fig. $12 \mathrm{OH}-58$ spiral-bevel pinion tooth crack propagation simulation after seven steps

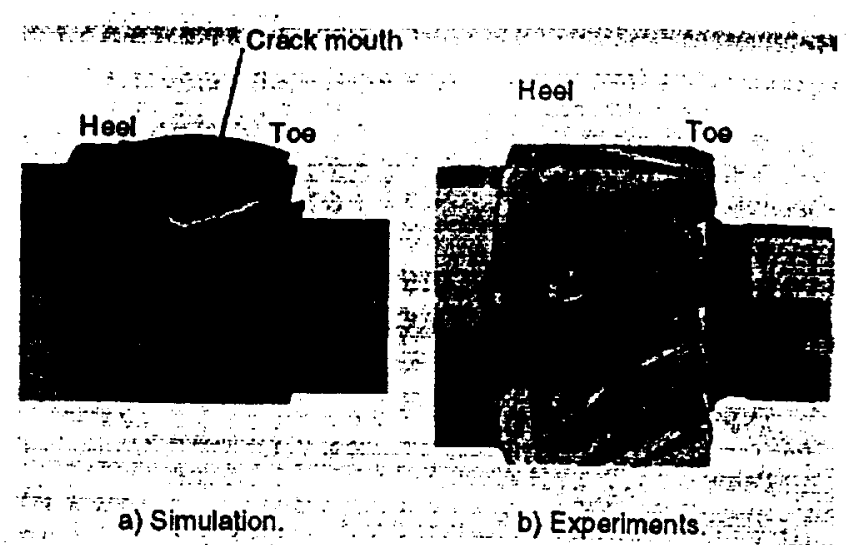

Fig. 13 Comparisoñ of $\mathrm{OH}-58$ spiral-bevel pinion tooth crack propagation simulation to experiments

from the tests. At the toe end, the simulation showed the crack progressing in a relatively straight path. This also matched the trend from the tests. Toward the latter stages of the simulation, however, the crack tended to taper toward the tooth tip at the toe end. This did not match the tests. One problem encountered in the simulation during the later steps was that the crack at the heel end of the tooth became close to the actual contact ellipses. It was felt that the crack-contact interaction may have influenced the trajectory predictions to cause the discrepancy.

Spievak [19] reported on another method to account for the non-uniform $K_{I I}$ to $K_{I}$ ratio during pinion tooth engagement. This method considered contributions from all load cases in the crack angle prediction scheme and presented a method to cumulate the load effects. From these studies, reported crack propagation simulation of an OH-58 pinion also predicted the erroneous taper toward the tooth tip at the toe end. Again, the crack-contact interaction may have influenced the trajectory predictions to cause the discrepancy. Spievak also reported on a simulation using only the load at the HPSTC. The results from that simulation were similar to that achieved in the current study. It should be noted that the proposed method in the current study to account for moving tooth loads for the three-dimensional analysis was extremely cumbersome. It is therefore felt that the analysis using only the load at the HPSTC appeared accurate as long as the crack did not approach the contact region on the tooth.

\section{Conclusions}

A study to determine the effect of moving gear tooth load on crack propagation predictions was performed. Two-dimensional analysis of an involute spur gear using the finite element method was investigated. Also, three-dimensional analysis of a spiralbevel pinion gear using the boundary element method was discussed. The following conclusions were derived:

1) A modified theory for predicting gear crack propagation paths based on the criteria of Erdogan and Sih was validated. This theory stated that as a cracked gear tooth was engaged in mesh, the crack extension started at the crack tip and grew in direction of the greatest tangential stress during mesh.

2) For two-dimensional analysis, crack simulation based on calculated stress intensity factors and mixed mode crack angle prediction techniques can use a simple static analysis in which the tooth load is located at the highest point of single tooth contact.

3) For three-dimensional analysis, crack simulation can also use a simple static analysis in which the tooth load is located at the highest point of single tooth contact as long as the crack does not approach the contact region on the tooth. 


\section{References}

[1] Nicoletto, G., 1993, "Approximate Stress Intensity Factors for Cracked Gear Teeth," Eng. Fract. Mech., 44, No. 2, pp. 231-242.

[2] Abersek, B., and Flasker, J., 1994, "Stress Intensity Factor for Cracked Gear Tooth," Theor. Appl. Fract. Mech., 20, No. 2, pp. 99-104.

[3] Sfakiotakis, V. G., Katsareas, D. E., and Anifantis, N. K., 1997, "Boundary Element Analysis of Gear Teeth Fracture," Eng. Anal Boundary Elem. , 20, No. 2, pp. 169-175.

[4] Inoue, K., and Kato, M., 1994, "Crack Growth Resistance Due to Shot Peening in Carburized Gears." Presented at the 30th AIANASMESAE/ASEE Joint Propulsion Conference, Indianapolis, IN.

[5] Blarasin, A., Guagliano, M., and Vergani, L., 1997, "Fatigue Crack Growth Predictions in Specimens Similar to Spur Gear Teeth," Fatigue Fract. Eng. Mater. Struct., 20, No. 8, pp. 1171-1182.

[6] Glodez, S., Pehan, S., and Flasker. J., 1998, "Experimental Results of the Fatigue Crack Growth in a Gear Tooth Root," Int. J. Fatigue, 20, No. 9, pp. 669-675.

[7] Arikin, M. A., Tarhan, A. I., and Yahoj, O. S., 1998, "Life Estimate of a Spur Gear with a Tooth Cracked at Fillet Region," Proceedings of the ASME De. sign Engineering Technical Conference, Atlanta, GA.

[8] Abersek, B., and Flasker, J., 1998, "Experimental Analysis of Propagation of Fatigue Crack on Gears," Exp. Mech. 38, No. 3, pp. 226-230.

[9] Lewicki, D. G., and Ballarini, R., 1997. "Effect of Rim Thickness on Gear Crack Propagation Path." ASME J. Mech. Des., 119, No. 1, pp. 88-95.

[10] Pehan, S., Hellen, T. K., Flasker, J., and Glodez, S., 1997, "Numerical Methads for Determining Stress Intensity Factors vs Crack Depth in Gear Tooth Roots," Int. J. Fatigue, 19, No. 10, pp. 677-685.

[11] Curin. T. J., Adey, R. A., Baynham, J. M. W., and Marais, P., 1998, "Fatigue Crack Growth Simulation for Complex Three-Dimensional Geomery and Loaded," Proceedings from the 2nd Joint NASAFAADDuD Cunference on Aging Aircraft, Williamsburg. VA.

[12] Lewicki, D. G., Sane, A. D., Drago, R. J., and Wawrzynek, P. A., 1999, "Three-Dimensional Gear Crack Propagation Studies," Proceedings of the 4th World Congress on Gearing and Power Transmission, Paris, France, 3, pp. 2311-2324.

[13] Ciavarella, M., and Demelio, G., 1999, "Numerical Methods for the Optimization of Specific Sliding. Stress Concentration, and Fatigue Life of Gears," Int. J. Fatigue, 21, No. 5. pp. 465-474.

[14] Wawrzynek, P. A., 1991, "Discrete Modeling of Crack Propagation: Theoretical Aspects and lmplementation Issues in Two and Three Dimensions," Ph.D. Disseration, Comell University.

[15] Rice, J. R., 1968, "A Path Independent Integral and the Approximate Analysis of Strain Concentration by Notches and Cracks," ASME J. Appl. Mech., 35, pp. 379-386.

[16] Lin, H. H., Huston, R. L., and Coy, J. J., 1988, "On Dynamic Loads in Parallel Shaft Transmissions: Part I-Modeling and Analysis," ASME J. Mech., Transm., Autom. Des., 110. No. 2, pp. $221-225$.

[17] Williams, M. L. 1957. "On the Stress Distribution at the Base of a Stationary Crack," ASME J. Appl. Mech., 24, No. 1, pp. 109-114.

[18] Erdogan, F., and Sih. G. C., 1963, "On the Crack Extension in Plates Under Plane Loading and Transverse Shear," J. Basic Eng., 85, pp. 519-527.

[19] Spievak, L. E. 1999, "Simulating Fatigue Crack Growth in Spiral Bevel Gears," M. Sc. thesis, Cornell University.

[20] Handschuh, R. F., and Litvin, F. L., 1991, "A Method for Determining SpiralBevel Gear Tooth Geometry for Finite Element Analysis," NASA TP-3096, AVSCOM TR-91-C-020.

[21] Litvin, F. L, and Zhang, Y.. 1991, "Local Synthesis and Tooth Contact Analysis of Face-Milled Spiral Bevel Gears," NASA Contractor Report 4342, AVSCOM Technical Report 90-C-028.

[22] Handschuh, R. F., and Kicher, T. P., 1996, "A Method for Thermal Analysis of Spiral Bevel Gears," ASME J. Mech. Des., 118. No. 4, pp. $580-585$.

[23] Paris, P. C., and Endogen. F., 1963. "A Critical Aralysis of Crack Propagation Laws," J. Basic Eng., 85, pp. 528-534.

[24] Au, J. J., and Ke. J. S., 1981, "Correlation Between Fatigue Crack Growth Rate and Fatigue Striation Spacing in AISI 9310 (AMS 6265) Steel," Fractography and Material Science, ASTM STP 733, pp. 202-221. 
